\title{
EFFECT OF SPIRULINA PLATENSIS ON REPRODUCTIVE PERFORMANCE OF RABBIT BUCKS
}

\author{
Sara F. Fouda ${ }^{1}$ and Rehab F. S. A. Ismail ${ }^{2}$ \\ ${ }^{1}$ Department of Poultry Production, Faculty of Agriculture, Mansoura University, Mansoura, Egypt. \\ ${ }^{2}$ Department of Animal Production, Faculty of Agriculture, Mansoura University, Mansoura, Egypt.
}

(Received 21/2/ 2017, Accepted 28/3/2017)

\section{SUMMARY}

\begin{abstract}
$\mathrm{T}$ This study was designed to investigate reproductive performance of adult New Zealand White (NZW) rabbit bucks as affected by oral administration of Spirulina platensis (S. platensis). Bucks were randomly distributed into 2 homogeneous groups (10 in each). The first group were orally received $3 \mathrm{ml}$ distilled water (control), while those in the second group were orally treated with $3 \mathrm{ml}$ distilled water containing S. platensis at a level of $700 \mathrm{mg} / \mathrm{buck}$ as daily oral for 5 weeks before semen collection period. Semen was collected twice weekly for 10 successive weeks by artificial vagina. On day of semen collection, reaction time (RT) and physical semen characteristics were determined. During the last week of collection, concentration of testosterone in blood serum (STC), and some biochemicals and antioxidant activity in seminal plasma were estimated. Results showed that the $S$. platensis orally administration bucks improved $(\mathrm{P}<0.01)$ LBW, testicular $(\mathrm{P}<0.001)$ and epididymal $(\mathrm{P}<0.01)$ weights, testicular length $(\mathrm{P}<0.01)$ and STC $(\mathrm{P}<0.001)$, and decreased RT $(\mathrm{P}<0.01)$ of bucks as compared to controls. Ejaculate volume and percentages of progressive sperm motility, livability, normality, and acrosomal damage as well as sperm cell concentration and total sperm output (motile, motile normal, motile live and total functional) significantly improved by $S$. platensis compared with controls. Also, semen $\mathrm{pH}$ value decreased $(\mathrm{P}<0.05)$ by $S$. platensis treatment. Concentrations of total fructose and total proteins were significantly higher in seminal plasma as affected by S. platensis treatment, while, concentrations of albumin (AL), globulin (GL) and AL: GL ratio were not affected by $S$. platensis treatment. Activity of total antioxidant capacity, glutathione S-transferase, superoxide dismutase, and glutathione peroxidase significantly increased, while TBARS concentration significantly decreased in seminal plasma of bucks treated with S. platensis, however, glutathione concentration was not affected. Conception rate and kindling rate, litter size and average bunny weight at birth improved in doe rabbits mated with bucks treated with $S$. platensis. In conclusion, S. platensis at a level of $700 \mathrm{mg} / \mathrm{buck}$ as oral administration for 5 weeks period to be used in natural mating or artificial insemination is recommended to be serving as a supportive treatment in the nutritional management to improve semen production of rabbit bucks, and fertility of doe rabbits mated with these bucks.
\end{abstract}

Keywords: Rabbit bucks, spirulina platensis, semen quality, fertility.

\section{INTRODUCTION}

Reproduction of rabbits plays a vital role in profitability of rabbits breeding (Ghazal et al., 2016). Artificial insemination (AI) is widely used on commercial scale in rabbit production and semen quality is the guarantee of successful AI in breeding rabbits (Castellini, 2008). Several endogenous and exogenous factors were reported to affect semen quality of rabbit (Sheteifa and Morsy, 2014). Appropriate protocols are needed to improve different characteristics of rabbit spermatozoa (Brun et al., 2002).

For improving the reproductive performances of animals, there was a development in biological farm system producers to use natural active compounds such as microalgae (Kistanova et al., 2009). Recently, microalga production such as blue-green alga (Spirulina), which is considered a promising microorganism, has a great attention to be a good alternative dietary source of proteins (Alvarenga et al., 2011). These microorganisms are classified into Spirulina platensis (S. platensis), Spirulina fusiformis and Spirulina maxima (Karkos et al., 2011).

Spirulina alga (SA) is a primitive planktonic photosynthetic filamentous cyanobacterium that has a simple structure but a complex composition. It has high feeding value with wide range of medicinal applications (Abu-Elala et al., 2016). The SA contains important compounds, in term of high protein 
content (60-70\% on dry matter basis) with all essential amino acids (Farag et al., 2016), vitamins ( $\mathrm{B}_{12}$ and $\beta$-carotene), poly-unsaturated fatty acids ( $\gamma$-linolenic acid), and minerals $(\mathrm{Ca}, \mathrm{Cr}, \mathrm{K}, \mathrm{Mg}, \mathrm{Cu}, \mathrm{Fe}, \mathrm{Na}, \mathrm{P}$, $\mathrm{Mn}, \mathrm{Zn}$ and Se (Hoseini et al., 2013). It also contains many photosynthetic pigments (phycocyanobilin chlorophyll and xanthophyll phytopigments) as reported by Gong et al. (2005); Bermejo et al. (2008), that makes SA a promising new dietary resource supporting the future production requirements of animals. The SA has various biological activities, impact effects as antioxidant (Kurd and Samavati, 2015), anti-inflammatory (Vide et al., 2015), antiviral, immune-modulatory (Sahan et al., 2015), antitumor (Konickova et al., 2014) and probiotics (Shanmugapriya et al., 2015) properties. In addition, $S A$ is believed to reduce toxicity, increase palatability and digestibility, and protected many organs against many drugs and toxic chemicals (Abdel-Daim et al., 2013). Spirulina treatment was reported to improve productivity and reproduction of animals and poultry, without side effects and more costs as compared to other synthetic products (El-Sabagh et al., 2014; Shanmugapriya et al., 2015).

The reproductive efficiency of rabbits depends on semen quality of bucks, environmental factors and the physiological status of the does (Theau-Clement and Roustan, 1992). The exposure of males to cold or heat stress, wind, ventilation, moisture, light and solar radiation can affect negatively on fertility by inducing the oxidative stress (Alejandro et al., 2014). This stressor leads to increasing free radicals accumulation, which causes damage of cell membrane DNA fragmentation of spermatogenic cells (ElDesoky et al., 2013). Normal sperm function needs a low level of reactive oxygen species (ROS) (ElTohamy and El-Nattat, 2010). However, ROS levels more than the total antioxidant capacity caused oxidative stress in the semen occurs, which clearly impair fertility (El-Tohamy and El-Nattat, 2010). Antioxidants protect cellular components from the damaging by cellular free radicals and ROS. When antioxidants are absent, at suboptimal level or not available at the precise place within the cell, where free radicals are formed, damage can occur (El-Tohamy et al., 2012).

Therefore, the specific aim of the present study was to investigate the efficacy of oral S. platensis administration on reproductive performance of New Zealand White (NZW) rabbit bucks, in terms of physical semen characteristics, and biochemical properties, antioxidant activity in seminal plasma.

\section{MATERIALS AND METHODS}

\section{Animals:}

Twenty NZW rabbit bucks at 6-7 months old and of 2750-2850 g live body weight (LBW) were used in this study. Bucks were randomly distributed into 2 homogeneous groups (10 in each) and allowed to acclimatize for one week before the beginning of experiment. Bucks were individually housed in galvanized wire mesh cages provided with feeders and automatic stainless steel nipple drinkers. All bucks were fed ad libitum on a commercial complete pelleted diet throughout the experimental period.

Bucks in the first group were orally received $3 \mathrm{ml}$ distilled water (control), while those in the second group were orally treated with $3 \mathrm{ml}$ distilled water containing $S$. platensis at a level of $700 \mathrm{mg} / \mathrm{buck}$ daily for 5 weeks as a treatment period.

\section{Collection and evaluation of semen:}

Semen was collected twice weekly for 10 weeks as a collection period from all bucks using an artificial vagina maintained at $42-45^{\circ} \mathrm{C}$ and a teaser doe. On day of semen collection, reaction time (RT) was estimated as the time elapsed from introducing buck up to complete ejaculation. Immediately after semen collection, ejaculates were kept at $37^{\circ} \mathrm{C}$ in water bath and transferred to the laboratory.

Semen was evaluated for ejaculate volume (EV) without gel mass and for $\mathrm{pH}$ value determination using a pH paper (Spezial-Indikatorpapier $\mathrm{pH}$ 5.5-9.0, MACHEREY-NAGEL. Germany). Also, percentages of progressive motility (PSM), livability (LS), and abnormality of spermatozoa (AS) were determined in each ejaculate at $37^{\circ} \mathrm{C}$. Sperm cell concentration (SCC) was estimated using Neubauer heamocytometer slide. Percentage of sperm with acrosomal damage (ASD) was determined by Giemsa stain procedure (Watson, 1975). In each ejaculate, total sperm output (TSO) was calculated by multiplying semen EV (ml) by SCC/ml; motile sperm output (MSO) was calculated by multiplying PSM (\%) by TSO; motile normal sperm output (MNSO) was calculated by multiplying normal sperm (\%) by TSO; motile live sperm output (MLSO) was calculated by multiplying LS by TSO, while total functional sperm fraction (TFSF) as the product of TSO by multiplying percentage of PSM x normality x livability (Correa and Zavos, 1994). 


\section{Serum testosterone concentration:}

Blood samples were collected from ear vein of 3 bucks in each group. Serum was obtained by blood centrifugation at $3000 \mathrm{rpm}$ for 15 minutes and carefully decanted into tubes and stored in a deep freezer at $-20^{\circ} \mathrm{C}$ until analysis. Serum testosterone concentration was analyzed by immunoassay (Biosource-Europe S.A. 8, rue de L'Lndustrie.B-1400 Nivelles. Belgium).

\section{Biochemical analysis of seminal plasma:}

Seminal plasma samples from all bucks were taken at the end of collection period by centrifugation of fresh semen for 15 minutes at $3000 \mathrm{rpm}$, then seminal plasma was separated and stored in deep freezer at $-20^{\circ} \mathrm{C}$ until analyses of concentration of total protein, albumin, globulin and total fructose as well as enzyme activity of aspartate (AST) and alanine (ALT) aminotransferases, acid (ACP) and alkaline (ALP) phosphatases using commercial kits (Bio-diagnostic Co., Recycling Crusher-SBM ${ }^{\circledR}$ ).

\section{Oxidative capacity in seminal plasma:}

Lipid peroxidation biomarkers, including total antioxidant capacity, TAC (Erel, 2004), glutathione content, GSH (Beutler et al., 1963), glutathione peroxidase, GPx (Chiu et al.,1976), glutathione Stransferase, GST (Habig et al.,1974), superoxide dismutase, SOD (Misra and Fridovich, 1972) and thiobarbituric acid-reactive substances, TBARS (Tappel and Zalkin, 1959) were assayed in seminal plasma using commercially available kits (Bio Diagnostic Research).

\section{Testicular measurements:}

At the end of semen collection period, three bucks from each group were weighed and slaughtered, then testes and epididymis were immediately removed, trimmed of adhering connective tissue and fats. The separated testes and epididymis were dried and weighed to determine their relative weights. Also, testicular measurements (length and width) were recorded.

\section{Fertility trails:}

For fertility evaluation, five bucks from each group were used for natural mating of 20 NZW nulliparous doe rabbits. Palpation of mated doe rabbits was carried out 10-12 days post-mating to determine conception rate (\%). Also, kindling rate, total number of borns (live and dead/doe) and viability rate at birth, and bunny and litter weights were recorded at birth.

\section{Statistical Analysis:}

The data obtained were analyzed using independent T- test using SAS (2002) software for control and treated groups.

\section{RESULTS AND DISCUSSION}

\section{Effect of S. platensis administration on:}

\section{Live body weight and reproductive organ characteristics:}

Rabbit bucks orally administrated with $S$. platensis at a level of $700 \mathrm{mg} /$ buck daily were significantly $(\mathrm{P}<0.01)$ heavier than those in control group (Table 1). Impact of S. platensis dietary addition on growth performance of rabbits was indicated also in broiler chicks (Shanmugapriya et al., 2015; Pandav and Puranik, 2015), fattening lambs (El-Sabagh et al., 2014) and Nile tilapia (Abu-Elala et al., 2016). The observed positive effect of $S$. platensis as an antioxidant on growth performance of rabbits in the present study is in agreement with the effect of different dietary additives such as selenium, folic acid and their combinations on increasing LBW of rabbit bucks (Kamel, 2012). Such effect of S. platensis on animal growth may be due to high contents of digestible protein, vitamin $\mathrm{B}_{12}$, amino acids and minerals (Farag et al., 2016). Also, bioactive constituents of $S$. platensis such as $\beta$-carotene, phycocyanin, $\gamma$-linolenic acid and phenolic compounds give this type of macrophytes its powerful antioxidant, antimicrobial, immunostimulant, and resistance against diseases (Lin et al ., 2010).

Regarding the testicular and epididymal characteristics, absolute and relative weights of testes and epididymis of rabbit bucks increased significantly due to oral administration of $S$. platensis compared with control group $(\mathrm{P}<0.001$ and $\mathrm{P}<0.01$, respectively). Only, testicular length of treated bucks was significantly $(\mathrm{P}<0.01)$ longer than those of control bucks, while testicular width was not affected significantly by $S$. platensis treatment (Table 1). 
Table (1): Effect of $S$. platensis treatment on live body weight and reproductive organ characteristics of NZW bucks.

\begin{tabular}{|c|c|c|c|c|}
\hline Item & Control group & Treatment group & T-Value & P-Value \\
\hline Initial live body weight $^{\top}$ & $2835 \pm 26.93$ & $2839 \pm 26.04$ & 0.12 & $0.90^{\mathrm{NS}}$ \\
\hline Final live body weight ${ }^{1}$ & $3067 \pm 20.63$ & $3175.0 \pm 34.36$ & 0.12 & $0.01 * *$ \\
\hline Testicular weight (g) & $6.13 \pm 0.08$ & $6.92 \pm 0.06$ & 7.34 & $0.001 * * *$ \\
\hline Relative testicular weight (\%) & $0.200 \pm 0.00$ & $0.213 \pm 0.01$ & 4.00 & $0.01 * *$ \\
\hline Epididymal weight $(\mathrm{g})$ & $2.22 \pm 0.02$ & $2.82 \pm 0.04$ & 12.73 & $0.001 * * *$ \\
\hline Relative epididymal weight $(\%)$ & $0.070 \pm 0.00$ & $0.083 \pm 0.01$ & 4.00 & $0.01 * *$ \\
\hline \multicolumn{5}{|l|}{ Testicular measurements $(\mathrm{cm})$ : } \\
\hline Length & $2.85 \pm 0.03$ & $3.08 \pm 0.04$ & 4.43 & $0.01 * *$ \\
\hline Width & $1.15 \pm 0.03$ & $1.22 \pm 0.02$ & 2.00 & $0.10^{\mathrm{NS}}$ \\
\hline
\end{tabular}

The noted increase in LBW and testicular weight (absolute and relative) is in association with increasing their length not in width. In this respect, testicular weight is largely dependent on the mass of the differentiated spermatogenic cells and reduction in the testicular weight indicates germ cell loss (Sarkar et al., 2003). In rabbit bucks, Ghazal et at. (2016) also showed that supplementing doum (Hyphaene thebaica) to diets caused significant improvement of testicular and epididymal weights, sexual accessory glands and pituitary gland. In male rats, Sudha et al. (2010) found that methanolic extract of Moringa leaves enhanced seminiferous tubules, testis and epididymal weight. These findings may indicate that administration of $S$. platensis improved LBW, testicular characteristics and epididymal weight, which may reflect an impact on semen production of rabbit bucks.

\section{Sexual desire:}

Results regarding the sexual desire of rabbit bucks indicated significant reduction in reaction time $(\mathrm{RT}, \mathrm{P}<0.001)$ and marked increase in serum testosterone concentration $(\mathrm{STC}, \mathrm{P}<0.01)$ in treated than in control bucks. This means that $S$. platensis treatment improved libido of rabbit bucks (Fig. 1).

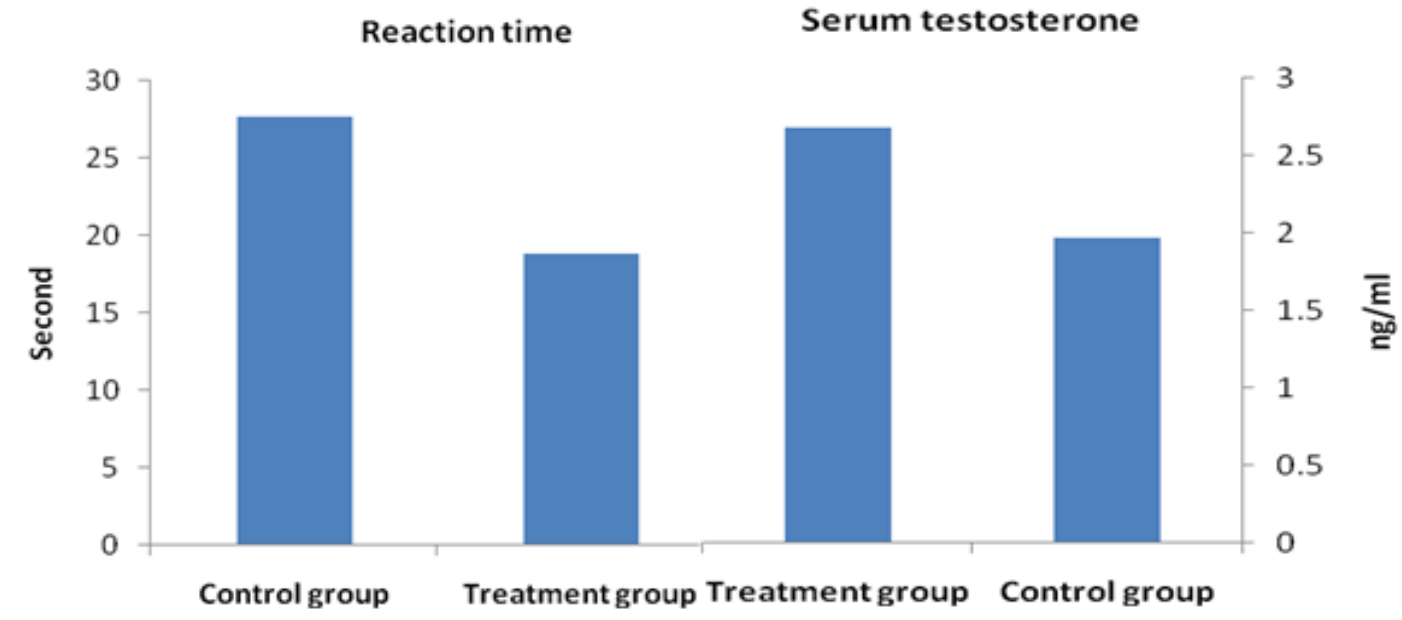

Fig. (1): Effect of $S$. platensis treatment on sexual desire NZW bucks.

In this respect, an improvement in total sexual libido (RT and STC) was reported in rabbit bucks treated with selenium plus vitamin E combination (Yassen et al.,2016), royal jelly as natural active compounds (El-Hanoun et al., 2014), red algae (Ali and Mervat, 2013) or lycopene addition as natural antioxidants (Mangiagalli et al., 2012). The improvement in libido of treated bucks may be due to antioxidant components of S. platensis (Rezvanfar et al., 2008). Testosterone is main male sex hormone, which plays a crucial role in the suitable development of reproductive organs and in the maintenance of male sexual characteristics. 


\section{Physical semen characteristics:}

Oral administration of $S$. platensis significantly improved all physical semen characteristics, including ejaculate volume (EV), progressive sperm motility (PSM), live sperm (LS), abnormal sperm (AS), acrosomal damage (ASD) and sperm cell concentration (SCC), and sperm output, involving total, motile, motile normal, motile live and total functional spermatozoa compared with untreated group. On the other hand, semen $\mathrm{pH}$ value significantly $(\mathrm{P}<0.05)$ decreased in treated than in control buck semen $($ Table2). The positive influence of $S$. platensis on semen volume and sperm quality was established in boars (Kistanova et al., 2009), and on sperm motility and semen concentration in rats (El-Desoky et al., 2013; Bashandy et al., 2016).

Table (2): Effect of $S$. platensis treatment on physical semen characteristics and sperm output of NZW bucks.

\begin{tabular}{|c|c|c|c|c|}
\hline Item & Control group & Treated group & T-Value & P-Value \\
\hline \multicolumn{5}{|l|}{ Physical semen characteristics: } \\
\hline Ejaculate volume (ml) & $0.52 \pm 0.08$ & $0.71 \pm 0.02$ & 2.30 & $0.04 *$ \\
\hline Progressive sperm motility (\%) & $67.14 \pm 2.64$ & $79.29 \pm 1.30$ & 4.12 & $0.001 * * *$ \\
\hline Live sperm $(\%)$ & $73.57 \pm 1.43$ & $84.14 \pm 0.70$ & 6.64 & $0.001 * * *$ \\
\hline Live : dead sperm ratio & $2.86 \pm 0.23$ & $5.37 \pm 0.24$ & 7.65 & $0.001 * * *$ \\
\hline Abnormal sperm $(\%)$ & $19.14 \pm 0.51$ & $13.57 \pm 0.65$ & 6.75 & $0.001 * * *$ \\
\hline Normal: abnormal sperm ratio & $4.22 \pm 0.51$ & $6.37 \pm 0.65$ & 6.75 & $0.001 * * *$ \\
\hline Acrosomal damage $(\%)$ & $18.14 \pm 0.34$ & $13.43 \pm 0.57$ & 7.09 & $0.001 * * *$ \\
\hline Sperm cell concentration $\left(\times 10^{6} / \mathrm{ml}\right)$ & $484.3 \pm 6.49$ & $577.1 \pm 14.9$ & 5.71 & $0.001 * * *$ \\
\hline Semen $\mathrm{pH}$ value & $7.41 \pm 0.05$ & $7.14 \pm 0.05$ & 3.70 & $0.03 *$ \\
\hline \multicolumn{5}{|l|}{ Sperm output (x10\% /ejaculate): } \\
\hline Total spermatozoa & $255.2 \pm 39.39$ & $406.5 \pm 9.04$ & 3.74 & $0.002 * *$ \\
\hline Motile spermatozoa & $170.4 \pm 27.09$ & $322.3 \pm 9.07$ & 5.32 & $0.001 * * *$ \\
\hline Motile normal spermatozoa & $205.7 \pm 31.81$ & $351.1 \pm 6.82$ & 4.47 & $0.001 * * *$ \\
\hline Motile live spermatozoa & $186.7 \pm 28.37$ & $341.9 \pm 7.39$ & 5.29 & $0.001 * * *$ \\
\hline Total functional spermatozoa ${ }^{1}$ & $100.3 \pm 15.58$ & $234.2 \pm 6.02$ & 8.02 & $0.001 * * *$ \\
\hline
\end{tabular}

In addition, treatment of rabbit bucks by royal jelly as natural active compounds in water (El-Hanoun et al., 2014), red algae (Ali and Mervat, 2013), lycopene addition as natural antioxidants to drinking water (Mangiagalli et al., 2012), dietary addition of enzymes (Gado et al., 2015) or organic selenium and folic acid (Kamel, 2012) had a positive effect on EV, semen quality and sperm output as compared to control bucks.

The improvement in semen characteristic of treated bucks may be due to antioxidant components of S. platensis (Rezvanfar et al., 2008), which has the capability to prevent cell damage through containing enzymatic and non-enzymatic antioxidant defense system that counteract the effects of ROS and protect cellular components from the damaging under normal or stress conditions (El-Tohamy et al., 2012).

It is of interest to note that the observed reduction in semen $\mathrm{pH}$ value in treated group may be attributed to higher SCC and PSM in semen of treated than in control bucks. It is well known that increasing sperm concentration with high viability was almost associated with remarkable increase in metabolic lactic acid as a result of sperm activity (Ayoub et al., 2000; Abdel-Khalek et al., 2001). Generally, improving all physical semen characteristics of treated bucks was in relation with increasing the level of STC as affected by S. platensis. Based on the foregoing results of sexual desire and semen characteristics in our study, rabbit bucks treated with $S$. platensis has impact on reproductive performance of rabbit bucks used for natural mating or those used for semen collection of AI.

\section{Biochemical analysis of seminal plasma:}

Chemical analysis of the seminal plasma revealed that concentrations of total fructose (TF) and total proteins (TP) were significantly higher in seminal plasma of treated than control bucks. While, albumin 


\section{Fouda and Ismail}

(AL), globulin (GL) concentrations and AL: GL ratio was not affected significantly by $S$. platensis treatment (Table 3). These results may indicate that $S$. platensis had positive effect on some biochemical contents in seminal plasma of NZW bucks. A similar trend was obtained by Nedeva et al. (2014), who found that the $S$. platensis addition in diets of pigs significantly increased the levels of TP and GL. The same effect was also obtained by El-Harairy et al. (2016), who showed that Moringa oleifera extract treatment significantly increased TP, AL and TF concentrations in seminal plasma of NWZ rabbits. Moreover, Kamel (2012) showed that feeding rabbit bucks on organic selenium and folic acid significantly increased TP, GL and TF in seminal plasma compared with those fed control diet. El-Masry et al. (1994) observed that TP and GL concentrations in rabbit seminal plasma significantly increased in response to selenium plus vitamin E supplements.

Table (3): Effect of $S$. platensis on concentration of some biochemicals and enzymatic activity in seminal plasma of NZW rabbit bucks.

\begin{tabular}{lcccc}
\hline Item & Control group & Treated group & T-Value & P-Value \\
\hline Biochemicals: & & & & \\
Total fructose (mg/dl) & $176.7 \pm 2.40$ & $241.3 \pm 4.09$ & 13.62 & $0.002^{* * *}$ \\
Total protein (g/dl) & $3.77 \pm 0.15$ & $4.57 \pm 0.12$ & 4.24 & $0.01^{* *}$ \\
Albumin (g/dl) & $2.33 \pm 0.20$ & $2.87 \pm 0.09$ & 2.41 & $0.07^{\mathrm{NS}}$ \\
Globulin (g/dl) & $1.44 \pm 0.19$ & $1.70 \pm 0.05$ & 1.37 & $0.24^{\mathrm{NS}}$ \\
Albumin/globulin ratio & $1.62 \pm 0.30$ & $1.69 \pm 0.06$ & 0.04 & $0.96^{\mathrm{NS}}$ \\
Enzyme activity (IU/l): & & & & \\
Alanine aminotransferase & $37.67 \pm 1.45$ & $25.67 \pm 1.20$ & 6.36 & $0.003^{* *}$ \\
Aspartate aminotransferase & $51.33 \pm 1.86$ & $40.67 \pm 1.20$ & 4.82 & $0.01^{* *}$ \\
Acid phosphatase & $31.67 \pm 0.88$ & $23.66 \pm 0.88$ & 6.41 & $0.003^{* *}$ \\
Alkaline phosphatase & $41.67 \pm 0.88$ & $35.67 \pm 1.20$ & 4.02 & $0.01^{* *}$ \\
\hline NS Not significant. $* *$ Significant at $P<0.01 . * * *$ Significant at $P<0.001$ & & &
\end{tabular}

In general, biochemical components in seminal plasma play a pivotal role in providing substrate energy forming essential link in the energy generating cycles in sperm metabolism in the process of fertilization and in the maintenance of constant osmotic pressure during semen preservation (Dhami and Kodagali, 1987). In this respect, fructose concentration in the semen has a positive relationship with the EV, SCC/ml, and percentages of PSM, LS, AS and acrosome status of spermatozoa (Ayoub et al., 2000).

On the other hand, enzymatic activity of AST, ALT, ACP and ALP was significantly $(\mathrm{P} \leq 0.01)$ lower in seminal plasma of treated than control group (Table 3). Similar effect was reported on activity of AST, ALT, ACP and ALP in semen of NZW bucks fed diet contained red algae (Ali and Mervat, 2013). Also, El-Masry et al. (1994) found that AST and ALT activities in whole rabbit semen significantly decreased as affected by selenium and vitamin E supplement.

The transaminase activities in semen are good indicators of semen quality because they measure sperm membrane stability (Dogan et al., 2009). Increasing the abnormal spermatozoa percentage in ejaculate may reflect high activity of transaminase enzymes into the extra-cellular fluid due to sperm membrane damage and ease of leakage of enzymes from spermatozoa (Seleem and Rowida, 2005; Zeidan et al., 2008). Therefore the present results indicated that $S$. platensis treatment may reduce the leakage of these enzymes and may emphasize that $S$. platensis plays an important role in sperm membrane integrity in semen of treated rabbit bucks.

\section{Oxidative capacity in seminal plasma:}

Activity of total antioxidant capacity (TAC), glutathione S-transferase (GST), superoxide dismutase (SOD), and glutathione peroxidase (GPx) significantly increased, while TBARS concentration significantly $(\mathrm{P}<0.001)$ decreased in seminal plasma of treated than in that of control group. However, $S$. platensis treatment did not influence glutathione (GSH) in seminal plasma of rabbit bucks (Table 4).

In accordance with the present results, Hwang et al. (2011) found that mice administrated with $S$. platensis significantly increased activity of GPx as compared to control. Also, the organic selenium, folic acid and their combination supplementation in rabbit feeds improved oxidative capacity in seminal plasma (Kamel, 2012). Treatment of bucks with royal jelly significantly increased TAC, GST, GPx, GSH and SOD, and significantly decreased TBARS in seminal plasma compared with control group (ElHanoun et al., 2014). 
Table (4): Effect of S. platensis treatment on oxidative capacity in seminal plasma of NZW bucks.

\begin{tabular}{lcccc}
\hline Item & Control group & Treated group & T-Value & P-Value \\
\hline TAC $(\mathrm{mmol} / \mathrm{L})$ & $1.03 \pm 0.04$ & $1.17 \pm 0.03$ & 2.82 & $0.04^{*}$ \\
GST $(\mathrm{IU})$ & $1.17 \pm 0.09$ & $1.77 \pm 0.09$ & 4.81 & $0.01^{* *}$ \\
SOD $(\mathrm{IU})$ & $7.90 \pm 0.21$ & $8.79 \pm 0.09$ & 3.89 & $0.01^{* *}$ \\
GSH $(\mathrm{mg} / \mathrm{dl})$ & $13.67 \pm 1.45$ & $17.33 \pm 1.45$ & 1.78 & $0.1^{\mathrm{NS}}$ \\
GPx $(\mathrm{mg} / \mathrm{L})$ & $4.70 \pm 0.36$ & $6.30 \pm 0.15$ & 4.09 & $0.01^{* *}$ \\
TBARS (nmol/ml) & $1.33 \pm 0.03$ & $0.96 \pm 0.04$ & 7.71 & $0.001^{* * *}$ \\
\hline NS: Not significant. * Significant at $P<0.05$. ** Significant at $P<0.01 . * * *$ Significant at $P<0.001$ &
\end{tabular}

Mammalian sperm included rabbit display high rates of metabolic activity and are rich in polyunsaturated fatty acids rendering them particularly susceptible to ROS-induced oxidation (Castellini $e t$ al., 2006). Lipid peroxidation is one of the major reactions leading to phospholipid loss, membrane damage and the loss of motility in mammalian spermatozoa (Mann and Lutwak-Mann, 1981). Based on these finding, the obtained results of $S$. platensis treatment on semen quality of rabbit bucks can be used for production of high non-enzymatic antioxidant contents (carotenoids, tocopherols, ascorbic acid, and chlorophyll derivatives) and enzymatic antioxidant (SOD, catalase and GPX) according to (Abd El-Baky, 2003; Abd El-Baky et al., 2007). Carotenoids and tocopherols in S. platensis can repair the oxidizing radical directly by its free radical scavenging activity through which they could inhibit the chain propagation steps during lipid peroxidation (Karpinski et al., 1999). The antioxidant activity of $S$. platensis could be also attributed to the presence of two main phycobiliproteins ingredients (phycocyanin and allophycocyanin) that are acting mainly against superoxide radicals (Chaiklahan et al., 2010). The polysaccharides from $S$. platensis had strong scavenging activities on hydroxyl radicals (Kurd and Samavati, 2015).

\section{Fertility trails:}

Fertility rate of doe rabbits naturally mated by bucks from treated and control groups, in terms of rates of conception and kindling, litter size and average bunny weight at birth improved by oral administration of S. platensis. The differences were significant only in total and live litter size as well as litter weight at birth (Table 5).

In agreement with the present results, fertility rate of multiparous doe rabbits did not significantly affected by mating with semen of bucks treated with lycopene addition (Mangiagalli et al., 2012). Also, hatchability, fertility and embryo mortality of female breeder turkeys were not affected after AI by semen enriched in vitamin E (Zaniboni et al., 2006). Although, Brun et al. (2002) reported that the mass motility significantly influenced the kindling rate, semen volume, percentage of motile sperm and concentration did not influence the kindling rate, but the number of motile sperm per ejaculate did.

Table (5): Reproductive performance of NZW doe rabbits naturally mated by bucks treated with $S$. platensis.

\begin{tabular}{lcccc}
\hline Item & Control group & Treated group & T-Value & P-Value \\
\hline Conception rate & $00 \pm 42.16$ & $100 \pm 0.00$ & 1.50 & $0.15^{\mathrm{NS}}$ \\
Kindling rate & $00 \pm 48.30$ & $80 \pm 42.16$ & 0.49 & $0.62^{\mathrm{NS}}$ \\
Total litter size/doe at birth & $43 \pm 0.37$ & $7.00 \pm 0.46$ & 2.60 & $0.01^{* *}$ \\
Live litter size/doe at birth & $86 \pm 0.26$ & $6.75 \pm 0.45$ & 3.48 & $0.004^{* *}$ \\
Bunny weight at birth $(\mathrm{g})$ & $.86 \pm 1.87$ & $52.50 \pm 1.04$ & 1.76 & $0.10^{\mathrm{NS}}$ \\
Litter weight at birth $(\mathrm{g})$ & $\cdot .0 \pm 15.42$ & $354.6 \pm 25.49$ & 3.95 & $0.001 * * *$ \\
\hline NS : Not significant. ** Significant at $P<0.01 . * * *$ Significant at $P<0.001$ & &
\end{tabular}

In addition, Kamel (2012) found improved fertility of rabbit bucks supplemented with natural active and antioxidants components such as organic selenium, folic acid and their combination as indicated by increasing litter size (total and alive) at birth for doe rabbits mated by these bucks as compared to control does. Similarly, NZW rabbit bucks fed diets supplemented with red alega recorded significant improvement in litter size and weight at birth compared with control group (Ali and Mervat, 2013). Improving litter size (total born) was significantly may be associated with increasing sperm cell 


\section{Fouda and Ismail}

concentration and all variables depending on it (sperm ouputs), particularly the number of total and motile sperm (Brun et al., 2002). Also, it was reported that reproductive efficiency of rabbits depends on semen quality of bucks, environmental factors and the physiological status of the does (Theau-Clement and Roustan, 1992).

\section{CONCLUSION}

The current study may suggest that Spirulina platensis at a level of $700 \mathrm{mg} / \mathrm{buck}$ daily as oral administration for 30 days period to be used in natural mating or artificial insemination is recommended to be serve as a supportive treatment in the nutritional management to improve semen production of rabbit bucks, and fertility of doe rabbits mated with these bucks.

\section{REFERENCES}

Abd El-Baky, Hanaa H., F.K. El-Baz and G.S. El-Baroty (2007). Enhancement of antioxidant production in Spirulina platensis under oxidative stress. American-Eurasian J. Sci. Res., 2: 170-179.

Abd El-Baky, Hanaa H. (2003). Over production of phycocyanin pigment in blue green alga Spirulina sp. and It's inhibitory effect on growth of ehrlich ascites carcinoma cells. J. Med. Sci., 3: 314-324.

Abdel-Daim, M.M., S.M.M. Abuzead and S.M Halawa (2013). Protective role of spirulina platensis against acute deltamethrin-induced toxicity in rats. PLoS. 9:1-9.

Abu-Elala, N.M., M.K. Galal, R.M. Abd-Elsalamm, O. Mohey-Elsaeed and N.M. Ragaa (2016). Effects of dietary supplementation of spirulina platensis and garlic on the growth performance and expression levels of immune-related genes in Nile Tilapia (Oreochromis niloticus). J Aquac Res. Development 7: 433.442 .

Abdel-Khalek, A., S.A. Darwish, A.F. Mehrez and M.B. Aboul-Ela (2001). Morpho-histmetric study on testis, epididymis and ampulla of fertile and sub-fertile Egyptian buffaloes. J. Agric. Sci. Mansoura Univ., 8: 4773-4786.

Alejandro, C., V. Abel, O. Jaime and S. Pedro (2014). Environmental stress effect on animal reproduction. J Adv Dairy Res. 2: 114-116.

Ali, W.A.H. and Mervat N. Ghazal (2013). In vivo and in vitro studies on the effect of Ganoderma on rabbit reproductivity, semen preservation and artificial insemination. J.Animal and Poultry Prod., Mansoura Univ., 12: 715 - 731.

Alvarenga, R. R., B. R. Paulo, C. Vinícius de Souza, G. Z. Márcio, W.J. José, R. Leonardo, M. Luziane and J.P. Luciano (2011). Energy values and chemical composition of spirulina (Spirulina platensis) evaluated with broilers. R. Bras. Zootec., 5: 992-996.

Ayoub, M., T. A. Taha, E. I. Abdel-Gowad, and H. Eman (2000). Variations in semen characteristics and serum testoterone and triiodothyronine levels in Barki, Damascus and their crossbred male goats throughout one year under subtropical conditions. Proc., 3rd All African Conf. Animal. Agri. \& ${ }^{11}$ th Conf. Egyptian Soc. Animal Prod. 459.

Bashandy, S. A. E., A. E. Sally, E. Hossam and M. A. Ibrahim (2016). Antioxidant potential of Spirulina platensis mitigates oxidative stress and reprotoxicity induced by sodium arsenite in male rats. Oxidative Medicine and Cellular Longevity.1:1-8.

Bermejo, P., E. Pinero, and A.M. Villar (2008). Iron-chelating ability and antioxidant properties of phycocyanin isolated from a protean extract of Spirulina platensis. Food Chem., 110: 436-445.

Beutler, E., O. Duron, and B.M. Kelly (1963). An improved method for the detection of blood glutathione. Journal of Laboratory and Clinical Medicine 61:882-888.

Brun, J.M., M.B. Theau-Clément, and G.B. Bolet (2002). The relationship between rabbit semen characteristics and reproductive performance after artificial insemination. Anim. Reprod. Sci., 70:139149. 
Castellini, C. (2008). Semen production and management of rabbit bucks. ${ }^{9}$ th World Rabbit Congress Verona - Italy. 265-277.

Castellini, C., Cardinali, R., Dal Bosco, A., Minelli, A. and O. Camici (2006). Lipid composition of the main fractions of rabbit semen. Theriogenology 65; 703-712.

Chaiklahan, R., N. Chirasuwan, W. Siangdung, K. Paithoonrangsarid and B. Bunnag (2010). Cultivation of Spirulina platensis using pig waste water in a semi-continuous process. J. Microbiol. Biotechnol., 20: 609-614.

Chiu, D.T.Y., F.H. Stults and A.L. Tappel (1976). Purification and properties of rat lung soluble glutathione peroxidase. Biochimica et Biophysica Acta 445:558-566.

Correa J.R. and Zavos P.M. (1994). The hypoosmotic swelling test: its employment as an assay to evaluate the functional integrity of the frozen-thawed bovine sperm membrane. Theriogenology. 42, 351-360.

Dhami, A. J. and S. B. Kodagali (1987). Correlation between biochemical and enzymatic constituents of serum of Suri buffalo bulls. Indian J. Anim. Sc., 57:1283.

Dogan, I., U, Polat and Z. Nur (2009). Correlations between seminal plasma enzyme activities and semen parameters in seminal fluid of Arabian horses. Iranian Journal of Veterinary Research, Shiraz University, 10: 119-124.

El-Desoky, G.E., S.A. Bashandy, I.M. Alhazza, Z.A. Al-Othman, M.A.M. Aboul-Soud (2013). improvement of mercuric chloride-induced testis injuries and sperm quality deteriorations by spirulina platensis in rats. PLoS ONE 3: 1-9.

El-Hanoun A.M., A.E. Elkomy, W.A. Fares and E.H. Shahien (2014). Impact of royal jelly to improve reproductive performance of male rabbits under hot summer conditions. World Rabbit Sci. 22: 241 248.

El-Harairy, M.A., Sh. M. Shamiah and A. A. Ghodaia (2016). Influence of oral whole extract from Moringa oleifera on semen characteristics of rabbits. J Animal and Poultry Prod., Mansoura Univ., 6; 217-224.

El-Masry, K.A., A.S. Nasr and T.H. Kamal (1994). Influences of season and dietary supplementation with selenium and vitamin E or zinc on some blood constituents and semen quality of New Zealand White rabbit males. World Rabbit Science 2:79-86.

El-Sabagh, M.R., M.A.A. Eldaim, D.H. Mahboub and M. Abdel-Daim (2014). Effects of Spirulina platensis algae on growth performance, antioxidative status and blood metabolites in fattening lambs. J. Agric. Sci., 6: 92-98.

El-Tohamy, M.M. and W.S. El-Nattat (2010). Effect of antioxidant on lead-induced oxidative damage and reproductive dysfunction in male rabbits. Journal of American Science, 11; 613-622.

El-Tohamy, M.M., M.S. Kotp, W.S. El-Nattat and A.H. Mohamed (2012). Semen characteristics and oxidative/antioxidative status in semen and serum of male rabbits supplemented with antioxidants during heat stress. Iranian Journal of Applied Animal Science., 2: 175-183.

Erel, O. (2004). A novel automated method to measure total antioxidant response against potent free radical reactions. Clin. Biochem., 37: 112-119.

Farag, M. R., A. Mahmoud, E. A. Mohamed and D. Kuldeep (2016). Nutritional and healthical aspects of Spirulina (Arthrospira) for poultry, Animals and Human. Int. J. Pharmacol., 12: 36-51.

Gado, H., M. Mellado, A.Z.M. Salem, A. Zaragoza and T.S.T. Seleem (2015). Semen characteristics, sexual hormones and libido of Hy-Plus rabbit bucks influenced by a dietary multi-enzyme additive. World Rabbit Sci.23: 111-120.

Ghazal, N.M., A.B. Safaa, W. A. H. Ali and M. R. Rowida (2016). Effect of supplementing doum (hyphaene thebaica) to diets on reproductive and productive traits in rabbits. Egypt. Poult. Sci. 3: 711 $-723$.

Gong, R., Y. Ding, H. Liu, Q. Chen and Z. Liu (2005). Lead bio-sorption and desorption by intact and pretreated Spirulina maxima biomass. Chemosphere, 58: 125-130.

Habig, W.H., M.J. Pabst and W.B Jakoby (1974). Glutathione S-transferases. The first enzymatic step in mercapturic acid formation. Journal of Biological Chemistry 249: 7130-7139. 


\section{Fouda and Ismail}

Hoseini, S.M., K. Khosravi-Darani and M. R. Mozafari (2013). Nutritional and medical applications of spirulina microalgae, Mini- Reviews in Medicinal Chemistry, 8:1231-1237.

Hwang, J.H., I.T. Lee, K.C. Jeng, M.F. Wang, R.C.W. Hou, S.M. Wu and Y.C. Chan (2011). Spirulina prevents memory dysfunction, reduces oxidative stress damage and augments antioxidant activity in senescence-accelerated mice. J. Nutr. Sci. Vitaminol., 57: 186-191.

Kamel, I. K. (2012). The effect of dietary organic selenium and folic acid supplementation on productive and reproductive performance of male rabbits under heat stress conditions. Egypt. Poult. Sci. I: 43-62.

Karkos, P.D., S.C. Leong, and C.D. Karkos (2011). Spirulina in clinical practice: Evidence-based human applications. Evid Based Complement Alternat Med. 53: 1053.

Karpinski, S., H. Reynolds, B. Karpinska, G. Wingsle, G. Creissen and P. Mullineaux (1999). Systemic signaling and acclimation in response to excess excitation energy in Arabidopsis . Science, 284: 654657.

Kistanova, E., Y. Marchev, R. Nedeva, D. Kacheva, K. Shumkov and B. Georgiev (2009). Effect of the Spirulina platensis induced in the main diet on boar sperm quality. Biotech animal husband 25: 54757.

Konickova, R., K. Vankova, J. Vanikova, K. Vanova and L. Muchova (2014). Anti-cancer effects of blue-green alga Spirulina platensis, a natural source of bilirubin-like tetrapyrrolic compounds. Ann. Hepatol., 13: 273-283.

Kurd, F. and V. Samavati (2015). Water soluble polysaccharides from Spirulina platensis: Extraction and in vitro anti-cancer activity. Int. J. Biol. Macromolecules, 74: 498-506.

Lin, Y.C., C. M. Tayag, C.L. Huang, W.C. Tsui and J.C. Chen (2010). White shrimp Litopenaeus vannamei that had received the hot-water extract of Spirulina platensis showed earlier recovery in immunity and up-regulation of gene expressions after pH stress. Fish Shellfish Immunol 29: 10921098.

Mangiagalli, M.G., V. Cesari, S. Cerolini, F. Luzi and I. Toschi (2012). Effect of lycopene supplementation on semen quality and reproductive performance in rabbit. World Rabbit Sci. 20: 141 $-148$.

Mann, T. and C. Lutwak-Mann (1981). Male reproductive function and semen. Springer-Verlag, Berlin, Germany.

Misra, H.P. and I. Fridovich (1972). The role of superoxide anion in the autoxidation of epinephrine and a simple assay for superoxide dismutase. Journal of Biological Chemistry 247: 3170-3175.

Nedeva, R., G. Jordanova, E. Kistanova, K. Shumkov, B. Georgiev, D. Abadgieva, D. Kacheva, A. Shimkus and A. Shimkine (2014). Effect of the addition of Spirulina platensis on the productivity and some blood parameters on growing pigs. Bulg. J. Agric. Sci., 20: 680-684.

Pandav, P.V. and P.R. Puranik (2015). Trials on metal enriched Spirulina platensis supplementation on poultry growth. Global J. Bio-Sci. Biotechnol., 4: 128-134.

Rezvanfar, M. A., R. A. Sadrkhanlou and A. Ahmadi (2008). Protection of cyclophosphamide-induced toxicity in reproductive tract histology, sperm characteristics, and DNA damage by an herbal source; evidence for role of free-radical toxic stress," Human and Experimental Toxicology, 12: 901-910.

SAS. (2002). Statistical user's Guide. Statistical Analysis System. INT Cary NC USA.

Sahan, A., O. Tasbozan, F. Aydin, S. Ozutok and C. Erbas (2015). Determination of some haematological and non-specific immune parameters in Nile Tilapia (Oreochromis niloticus L., 1758) fed with Spirulina (Spirulina platensis) added diets. J. Aquacult. Eng. Fish. Res., 1: 133-139.

Sarkar, M., G. R. Chaudhuri, A. Chattopadhyay and N. M. Biswas (2003). Effect of sodium arsenite on spermatogenesis, plasma gonadotrophins and testosterone in rats, Asian Journal of Andrology, 1:2731.

Seleem, T.S.T. and Rowida M. Riad (2005). Enzymatic activity and fertilizing ability of rabbit semen supplemented with Nigella Sativa extraction. The 4th Inter. Con. on Rabbit Prod. in Hot Clim., Sharm El-Sheikh, Egypt,183-189. 
Shanmugapriya, B., S.S. Babu, T. Hariharan, S. Sivaneswaran and M.B. Anusha (2015). Dietary administration of Spirulina platensis as probiotics on growth performance and histopathology in broiler chicks. Int. J. Recent Scient. Res., 6: 2650-2653.

Sheteifa, M.A.M and W.A. Morsy (2014). Effect of green tea (camellia sinensis) as dietary supplements on semen quality and testosterone profile in rabbits. J. Animal and Poultry Prod., Mansoura Univ., 1: $1-13$.

Sudha, P., M.B.A. Syed, S. S. Dhamingi and K. C. Gowda (2010). Immunomodulatory activity of methanolic leaf extract of Moringa Oleifera in animals. Indian J. Physiol Pharmacol, 2:133-140.

Tappel, A.L. and H. Zalkin (1959). Inhibition of lipid peroxidation in mitochondria by vitamin E. Arch. Biochem. Biophys. 80: 333-336.

Theau-Clement, M. and A. Roustan (1992). A study on relationships between receptivity and lactation in the doe, and their influence on reproductive performances. J. Appl. Rabbit Res. 15: 412-421.

Vide, J., A. Virsolvy, C. Romain, J. Ramos and N. Jouy (2015). Dietary silicon-enriched Spirulina improves early atherosclerosis markers in hamsters on a high-fat diet. Nutrition, 31: 1148-1154.

Watson, P.F. (1975). Use of Giemsa stain to detect changes in acrosomes of frozen ram spermatozoa. Vet. Res., 97: 12-15.

Yaseen,M. A., F. E. El-Azzazi, Eman Abdel-Halim and H. A. Khalil (2016). Effect of age, and vitamin E and selenium administration on semen characteristics of New Zealand White rabbit bucks. Egypt. Poult. Sci.2:5 $01-511$.

Zaniboni, L., R. Rizzi and S. Cerolini (2006). Combined effect of DHA and $\alpha$-tocopherol enrichment on sperm quality and fertility in the turkey. Theriogenology, 65: 1813-1827.

Zeidan, A.E.B., A.A. El-Zaiat, M.F.S. Hanna, and T.S.T. Seleem (2008). Effect of centrifugation on viability, acrosomal status and enzymatic activity of spermatozoa and sex ratio of rabbit kits. 1st Egyptian Conference on Rabbit Sciences, Animal Production Department, Faculty of Agriculture, Cairo University, Giza, Egypt,114-123. 


\section{Fouda and Ismail}

تأثير فطر الاسبيرولينا على الأداء التناسلى لذكور الارانب

سارة فكرى فوده1 و رحاب فوزى صديق عبد الفتاح اسماعيل 2

"قسم انتاج الدواجن - كلية الزراعة - جامعة المنصورة- مصر.

2قسم انتاج الحيوان - كلية الززاعة - جامعة المنصورة- مصر.

يهدف هذا البحث الى دراسة تأثير التجريع بفطر الاسبيرولينا عند مستوى 700 ملليجر ام/ذك يوميا على الاداء التناسلى لذكور

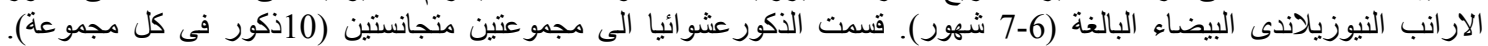

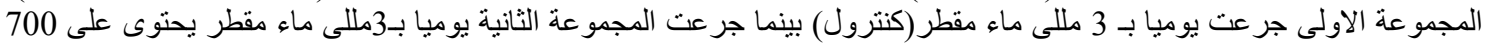

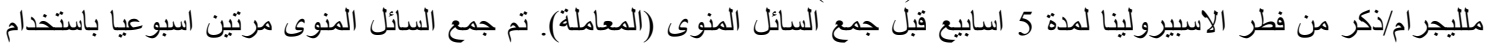

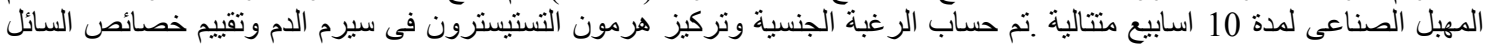

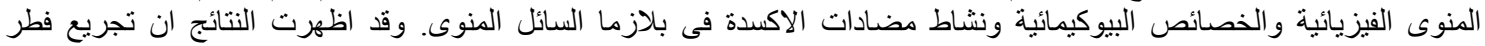

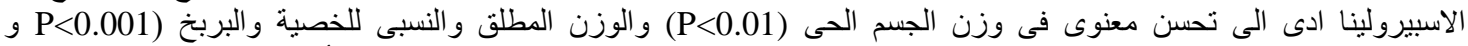

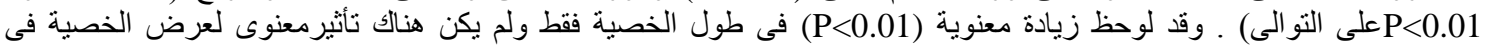

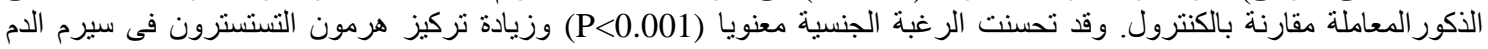

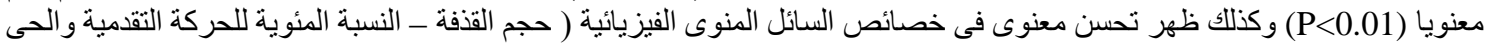

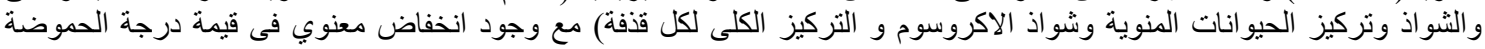

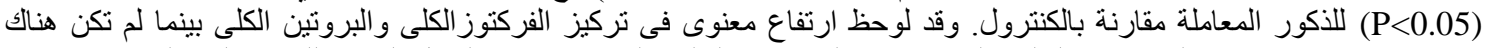

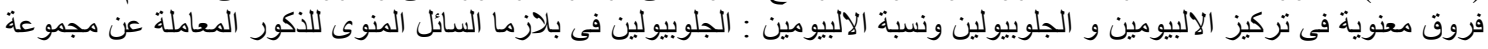

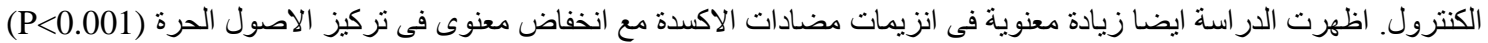

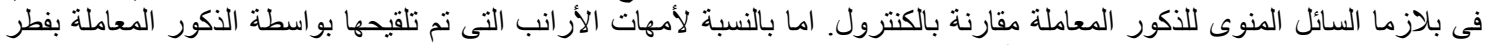

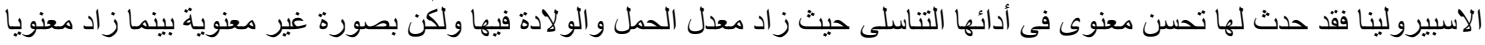

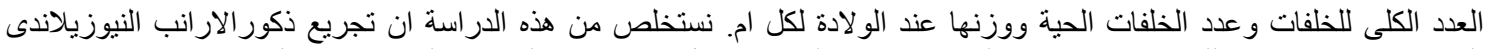

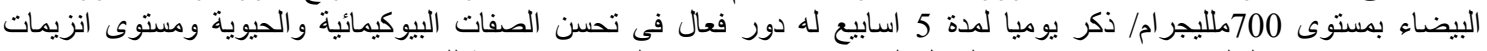

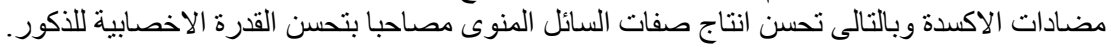

